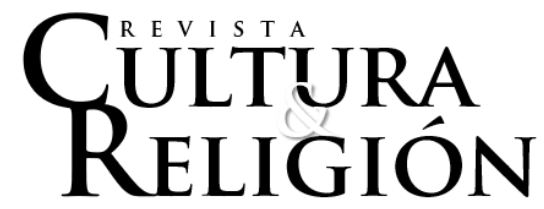

Vol. XV, No 1 (2021) pp. 299-329

Recibido: 29 de diciembre, 2020

Aceptado: 5 de mayo, 2021

\title{
NUESTRA ARBITRARIA Y CADA VEZ MÁS IMPRODUCTIVA FRAGMENTACIÓN DEL CAMPO DE ESTUDIOS DE LA RELIGIÓN
}

Our arbitrary and increasingly unproductive fragmentation of the field of religious studies

\author{
Alejandro Frigerio* \\ Universidad Católica Argentina/CONICET \\ ORCID: 0000-0003-0917-3103
}

\section{Resumen}

En este trabajo se argumenta que en los estudios de la religión predomina una delimitación excesivamente restricta del "campo religioso", el cual posee límites borrosos y superposiciones con otros campos "vecinos" pobremente definidos (espiritualidad, esoterismo, religiosidad popular, salud). Esto se debe principalmente a la utilización de perspectivas teóricas que son simultáneamente catolicocéntricas, modernocéntricas y eclesiocéntricas, y a una aplicación poco reflexiva del concepto de "campo religioso" de Bourdieu. La diferenciación arbitraria en subáreas de especialización e incumbencia produce ámbitos de especialización académica con poca comunicación entre estudiosos, dificultando interpretaciones abarcadoras e integradoras de las subáreas. Se brinda así una visión muy empobrecida y restringida de la "diversidad religiosa", fragmentando demasiado artificialmente nuestro objeto de estudio, y esencializando diferencias entre actividades y actores que en la vida cotidiana 
de los sujetos están muy entrelazados. Se proveen dos ejemplos empíricos que muestran cómo esta subdivisión invisibiliza la diversidad religiosa en el pasado argentino y dificulta su comprensión.

Palabras clave: religión, espiritualidad, religiosidad popular, esoterismo, salud.

\begin{abstract}
In this article, the authors argue that an excessively restrictive limitation of the "religious field" dominates religious study that has blurred borders and overlaps other "neighboring" fields that are poorly defined (spirituality, esoterism, popular religiosity, health). This is mainly due to the use of theoretical perspectives that are simultaneously focused on Catholicism, modernity and Ecclesiastic beliefs and the application of Bourdieu's concept of "religious field" that involves little reflection. The arbitrary differentiation of specialization and purview into sub-areas produces areas of academic specialization that have little communication between scholars. This stands as an obstacle to expansive and integrative interpretations of the sub-areas. As such, a very impoverished and restricted vision of "religious diversity" is offered, fragmenting our subject of study in an excessively artificial way and essentializing differences between activities and actors that are very much intertwined in daily life. Two empirical examples are provided that show how this subdivision makes invisible the religious diversity of Argentina's past and stands in the way of its understanding.
\end{abstract}

Keywords: religion, spirituality, popular religiosity, esoterism, health.

\title{
Introducción
}

La diversidad religiosa es evidente en las calles y barrios de nuestras sociedades latinoamericanas (aunque con importantes diferencias de grado de acuerdo al país), pero no se ve reflejada adecuadamente en nuestros análisis académicos. En parte, se debe a la tiranía que ya casi devino epistemológica 
que (parecen) ejercer los estudios cuantitativos (cuyas limitaciones todos conocemos, pero sobre las que mayormente callamos y el hacerlo nos impide justipreciar la verdadera dimensión de nuestras sociedades "aún mayoritariamente católicas"). Pero también porque la acumulación de una cantidad cada vez mayor de estudios etnográficos, interesantes en sí mismos, no nos permite sin embargo avanzar hacia un big picture de la realidad religiosa nacional o continental.

Esto es porque de manera habitual, nuestros presupuestos analíticos más generales acerca de la "religión", o de "la religión en la modernidad" (aun en nuestra "modernidad latinoamericana"), provenientes mayormente de la sociología, no son cuestionados sino repetidos, acríticamente, de manera tozuda y tenaz. Seguimos afirmando desde hace muchos años - pero todavía lo damos como una novedad o algo digno de mencionar en casi cada artículo- que la religión no desparece en la modernidad, sino que se recompone (cómo y por qué, es otro cantar que parece no importarnos demasiado); nos extrañamos y debemos explicar continuamente cuando la religión aparece en el espacio público o en medios de comunicación; creemos que las devociones populares crecen $y$ persisten por causa de nuestra "matriz cultural sincrética latinoamericana" -e ignoramos los esfuerzos de miles de individuos por mantenerlas y expandirlas. Repetimos continuamente que hubo un momento en que todos éramos católicos, pero ya no -por culpa de los pentecostales principalmente- y que ahora tenemos un mercado religioso en el cual los individuos eligen libremente y conforman su "religión a la carta".

Todas estas son cosas que "ya sabemos", que repetimos en cada congreso y en demasiadas publicaciones cuyos datos podrían conducirnos hacia otros caminos interpretativos si no los leyéramos siempre a la luz de nuestras consabidas y legitimadas "grandes teorías". Las "sabemos" también, porque no solemos dialogar lo suficiente con los estudios históricos de nuestros países, que nos mostrarían similitudes entre el pasado y el presente que preferimos ignorar -o que nos llevarían a dudar de la veracidad de ese pasado construido muchas veces sobre la base de la utilización de teorías desarrolladas en Europa 
o en Estados Unidos. Intentar desandar algunos de estos lugares comunes de nuestro conocimiento (más precario de lo reconocido) es una tarea ardua, pero que debe ser emprendida, a riesgo de que la cantidad cada vez mayor de estudios que vamos realizando comience a rendir, como ya sucede, de manera cada vez más decreciente, al estar fundados en grandes teorías cuya validez es ya a esta altura dudosa o poco productiva.

En esta oportunidad quiero llamar la atención hacia un importante, pero generalmente ignorado factor de distorsión de nuestros análisis que ayuda a ocultar nuestra diversidad religiosa: las divisiones muy arbitrarias pero naturalizadas que realizamos en el estudio de la "religión". ${ }^{1}$ Nuestras perspectivas teóricas dominantes llevan a una construcción muy específica del "campo religioso" (en rojo), que tiene límites borrosos y superposiciones con otros campos "vecinos" pobremente definidos. La siguiente figura intenta resumir esta división visualmente:

Figura $\mathbf{N}^{\circ}$ 1: Subáreas de incumbencia en el estudio de la "religión" y campos conexos

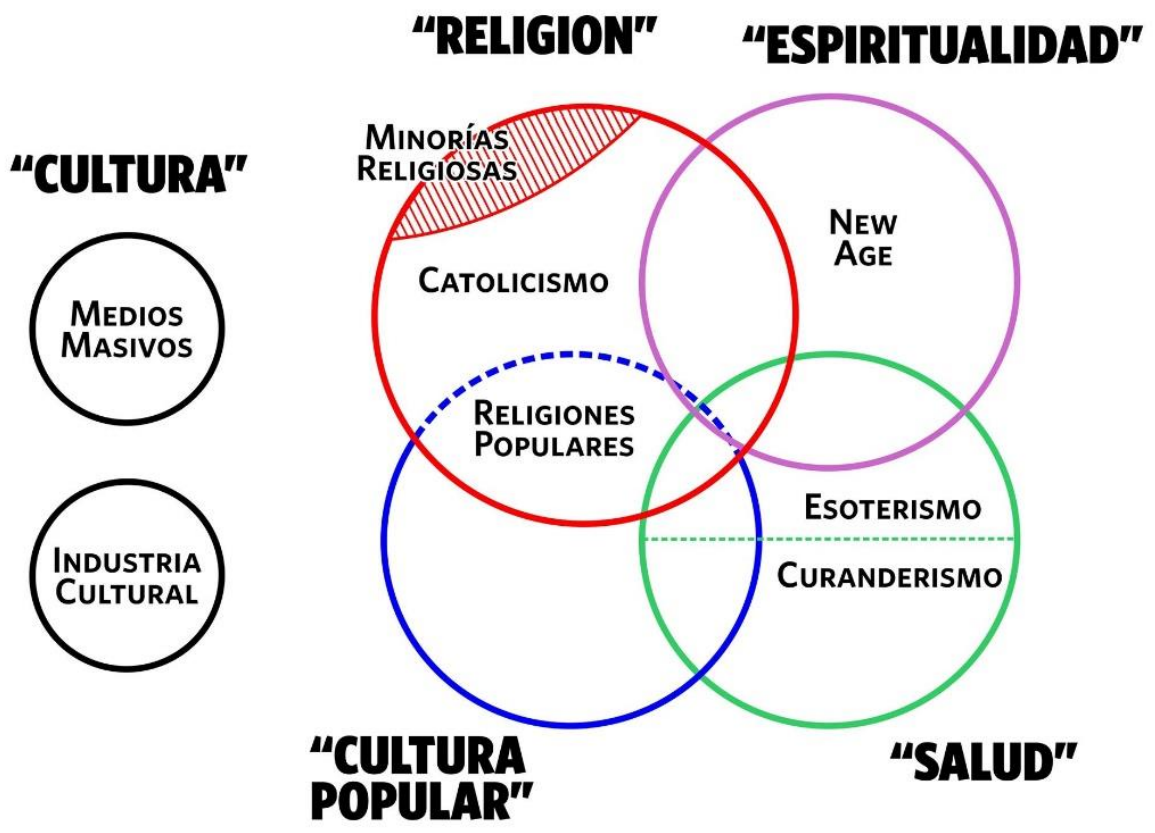

Fuente: elaboración propia.

\footnotetext{
${ }^{1}$ Estas reflexiones están basadas principalmente en mi conocimiento del caso argentino, pero también pueden ser extendidas a otros países. 
La mayor parte de los trabajos cualitativos, y casi todas las investigaciones cuantitativas, considera al campo religioso propiamente dicho (en la Figura $\mathrm{N}^{\circ}$ 1, el círculo rojo) como el de las "religiones" -compuestas por grupos con determinado grado avanzado de organización (usualmente correspondiente al tipo "iglesia" o "secta"), con cierta perdurabilidad en el tiempo y, sobre todo, que proveen identificaciones religiosas diferenciales y socialmente legitimadas. ${ }^{2}$ Así, el "campo religioso" propiamente dicho está compuesto mayormente por el catolicismo, y por las "minorías religiosas" reconocidas como tales: el Islam, el judaismo, el protestantismo histórico, los evangélicos y pentecostales, los testigos de Jehová, los mormones, los adventistas, los budistas y (con suerte) los umbandistas, entre otras posibilidades (segmento sombreado en el círculo rojo de la figura $\mathrm{N}^{\circ} 1$ ).

Un subsegmento algo más desdibujado de este campo lo compone la "religiosidad popular", que suele estar incluida analíticamente entre el catolicismo y la cultura popular. Es considerada parte del "campo religioso", pero en continua tensión con las creencias socialmente legítimas y en peligro constante de derrapar hacia el curanderismo o la magia. Dos campos de estudio tradicionales, pero ya considerados más periféricos respecto de la religión serían el esoterismo y el curanderismo. Ambos, pero el segundo con más intensidad, relacionados también o considerados parte del estudio de la salud, particularmente por quienes estudian sistemas no biomédicos de curación y su relación con el sistema biomédico oficial. ${ }^{3}$

${ }^{2}$ La Figura $\mathrm{N}^{\circ} 1$ es meramente indicativa. Su propósito es apenas ilustrar las subáreas de estudios más comunes o relevantes y su superposición. Intenta reflejar de manera aproximada la práctica académica actual en Argentina, y no un "deber ser" teórico-conceptual -como argumento en el trabajo. El tamaño de los subsegmentos (de los círculos azul, verde y magenta) que se superponen dentro del campo "religión" podría ser mayor o menor de acuerdo a cómo lo visualiza cada estudioso/a.

${ }^{3}$ El esoterismo se liga a salud principalmente cuando se lo concibe, más contemporáneamente, en relación con la Nueva Era (New Age) y el circuito alternativo de terapias, o, más históricamente, cuando se lo liga al espiritualismo, el magnetismo, el hipnotismo, etc. 
Un campo cuya relevancia creció en los últimos años, y cuya relación con el de la religión es aún algo incierta es el de la "espiritualidad". Es una categoría pretendidamente analítica, pero que no se separa fácilmente de los significados que se le atribuyen émicamente. Quizás por eso todavía discutimos si la espiritualidad forma parte del campo religioso, o si es un concepto alternativo y más apropiado que el de religión para caracterizar la forma que esta estaría tomando en la modernidad tardía; o si sería una modalidad de "neoesoterismo", o una nueva forma de referirnos a la New Age (o a su forma más masiva contemporánea) (Frigerio, 2013, 2016).

Varios de los investigadores más especializados en todos estos temas no parecen considerar que su actividad entre, necesariamente, dentro del estudio de la religión. De hecho, su desarrollo por fuera del área de estudios parece favorecer su importancia académica, ya que los posiciona como creadores de nuevos campos de estudio local, con contactos privilegiados con quienes ya lo hacen en otros países, particularmente del mundo universitario anglófono o francoparlante. Muchos apenas van a congresos de religión, o solo ocasionalmente publican en revistas especializadas en religión, y prefieren denominarse como antropólogos de la salud, especialistas en culturas populares, o en "esoterismo" u "ocultismo" o, aun, en "espiritualidad".

De manera aún más lejana y separada del campo religioso, tenemos quienes estudian la industria cultural y los medios de comunicación que poca atención le suelen prestar al tema religión. Algunos sociólogos o antropólogos de la religión se han aventurado en el tema de la industria cultural, pero generalmente y principalmente, en las industrias culturales desarrolladas por grupos religiosos o sus medios de comunicación -pocos aún le prestan atención a los medios y a las industrias culturales seculares como transmisores o dinamizadores, pero también creadores, de contenidos religiosos. ${ }^{4}$

${ }^{4}$ Para industrias culturales o medios de confesiones religiosas, ver la compilación de Algranti (2013) y el trabajo de Miguel (2013); para industrias culturales seculares y medios seculares, ver Semán (2002), Semán y Battaglia (2012), Semán y Rizo (2013), Viotti $(2015,2018)$ y Frigerio $(1993,2000)$. 
Estas diferenciaciones arbitrarias -que desembocan en compartimientos naturalizados casi estancos- brindan una visión muy empobrecida y restringida de la diversidad religiosa, ya que esta es ubicada como tan solo una parte muy pequeña del campo religioso: la que no corresponde al catolicismo (de nuevo: los evangélicos, judíos, islámicos, mormones, testigos de Jehová, umbandistas, etc.; correspondiente al segmento sombreado en la figura $\mathrm{N}^{\circ} 1$ ).

De esta manera, se fragmenta demasiado artificialmente nuestro objeto de estudio, y se esencializan las diferencias entre actividades y actores que en la vida cotidiana de los sujetos están muy entrelazados. Sobre todo, se oculta una gran cantidad de creación y práctica de diversidad religiosa, que sucede en todas estas áreas, ya que solo nos permite ver religión o actividad religiosa dentro del campo socialmente legitimado de la religión y de las religiones. Sin embargo, en todas estas áreas, heurísticamente colindantes con el campo religioso (social y académicamente legitimado), se postulan nociones acerca de cuáles serían los seres suprahumanos con los cuales podemos entablar relaciones y cuáles serían las mejores maneras de hacerlo. ${ }^{5}$

A través de la inagotable multiplicidad de grupos esotéricos, de curanderos, de agentes de religiosidad popular, o de gurúes que proponen las más diversas formas de espiritualidad que existen en nuestras sociedades, es que se postula la naturaleza muy diversa de seres suprahumanos con los que debemos relacionarnos y las diferentes formas de hacerlo (dentro de teologías trascendentes o inmanentes; ver Frigerio, 2016). Aun cuando muchos de estos seres suprahumanos sean los mismos propuestos por las religiones socialmente legitimadas, sus características, jerarquizaciones, necesidades, etc. son

\footnotetext{
${ }^{5}$ En otros trabajos propuse y defendí la necesidad de adoptar una definición de religión que -a diferencia de las que usamos habitualmente- no dependa tanto de la existencia de: a) determinado tipo de grupos religiosos (iglesias o sectas), b) que tampoco lo haga de creencias con un grado complejo de sistematización (propias de ciertas élites religiosas), c) ni de la necesaria producción de identificaciones sociales religiosas. Sugerí que una definición cercana a las de la perspectiva de la religión vivida (lived religion) nos brindaría visiones más realistas, y menos normativas, de la experiencia religiosa cotidiana de las personas. Propuse, entonces, que sería de utilidad analítica concebir a la religión como "una red de relaciones que involucra a los humanos con una serie de seres o poderes suprahumanos" (Frigerio, 2018, p. 76).
} 
radicalmente reformuladas en todos estos ámbitos y por todos estos agentes que no solemos considerar como "religiosos". Por su falta de legitimación social (y académica) no los vemos como productores de religión, pero en la vida cotidiana de las personas pueden adquirir una relevancia que los agentes oficiales de las iglesias instituidas no alcanzan, y se tornan importantes productores de diversidad religiosa (invisibilizada por nuestras anteojeras teóricas).

\section{1. Áreas de especialización temática con preocupaciones y presupuestos teórico-conceptuales propios}

Además de la invisibilización de la diversidad religiosa, la división en subáreas temáticas mayormente estancas tiene otras consecuencias negativas: se forman ámbitos de especialización académica con poca comunicación entre estudiosos, lo que dificulta interpretaciones abarcadoras (y/o comparativas y/o transversales) entre las subáreas, Quienes estudian antropología de la salud (por más que lo hagan entre grupos religiosos) prefieren interactuar con sus pares de otros países que realizan un recorte teórico similar antes que con quienes estudian religión en su propio país, y lo mismo vale para quienes estudian esoterismo, por ejemplo.

De esta manera, cada subárea de especialización desarrolla sus propias perspectivas teóricas, sus preguntas de investigación, sus temas principales de estudio y las bibliografías relevantes, lo que los lleva a trabajar entonces con supuestos teóricos y protagonistas sociales muy específicos. Quienes estudian la religión, la encuentran en grupos religiosos del tipo iglesia o secta; quienes analizan la espiritualidad, la encuentran en individuos autónomos (y casi solitarios) en búsquedas espirituales (seekers). Los estudios sobre religiosidad popular y curanderismo postulan (y por lo tanto, encuentran) individuos sobredeterminados por lógicas culturales -sincréticas u holísticas- o por etiologías premodernas no biomédicas. Quienes estudian esoterismo, generalmente se focalizan en grupos esotéricos que responden a determinada 
tradición esotérica -y su atractivo suele ser develado apelando a determinados imaginarios de época (que volverían a determinadas afirmaciones seudocientíficas posibles, por ejemplo).

Visto así, los conocimientos adquiridos en cada área difícilmente se articulan con los desarrollados en las otras, y mucho menos se encaja todo dentro de una teoría abarcativa sobre la naturaleza y función de estos agentes, grupos y contextos de producción de diversidad religiosa dentro de la economía religiosa de nuestras sociedades. ${ }^{6}$ Además de no posibilitar análisis abarcativos, difícilmente se utilicen los conceptos paradigmáticos de un área para comprender las otras: no hay "espiritualidad" en la religiosidad popular ni tampoco parece haber allí seekers "autónomos"; el holismo parece corresponderle solo a la religiosidad popular y no parecen haber búsquedas de salud en el campo de las religiones (¿cuántos estudios de pentecostalismo y salud conocemos, pese a que la sanación es sin duda una de los atractivos de estas iglesias?). ${ }^{7}$ Corremos, entonces, el peligro de crear (o haber creado) diferentes áreas de actividad mágico-religiosa-espiritual estereotipadas, cerradas y validadas con cada nuevo análisis porque partimos siempre de los mismos presupuestos "correspondientes" al área. Naturalizamos así la división arbitraria -que nunca está bien fundamentada ni definida-, los conceptos que le son "propios" y "pertinentes" a cada área y las teorías que les "corresponden".

Nuestra creación de compartimientos estancos, autovalidados, tiene otro efecto pernicioso: borra la diversidad religiosa de nuestros análisis más generales. Nunca parecemos tomar suficientemente en consideración que casi todos los que transitan por grupos esotéricos, o se declaran "espirituales y no religiosos", al ser preguntados por su identificación religiosa, probablemente

\footnotetext{
${ }^{6}$ Siguiendo a Stark y Finke (2000), considero la economía religiosa como "el total de la actividad religiosa aconteciendo en una sociedad" (2000, p. 193). Prefiero esta expresión a la de campo religioso porque veo este concepto demasiado sesgado hacia las creencias y prácticas que los especialistas socialmente legitimados consideran religión -0 , al menos, en su utilización local. Como argumenté en otro trabajo, sin embargo, mi definición de "religión" es diferente de la de Stark y Finke (Frigerio, 2020).

${ }^{7}$ Comparemos la cantidad de estudios de pentecostalismo y política con los de pentecostalismo y salud y consideremos cuál de estos dos aspectos es más importante en la vida cotidiana de los creyentes y las iglesias.
} 
responderían: "católicos". De esta manera, la diversidad religiosa aparece en los estudios específicos cualitativos, pero es borrada o al menos licuada $u$ homogeneizada en buena parte de los estudios cuantitativos, porque la diversidad de creencias y prácticas es barrida debajo de la alfombra de la uniformidad identificatoria (aunque hay que reconocer, claro, que la calidad y perspicacia de los estudios cuantitativos es muy diferente de país en país).

Para interpretar toda esta variedad de prácticas y creencias de quienes se declaran católicos, resta entonces solo apelar a la diversidad interna del catolicismo, cuando lo que está en juego muchas veces en esta "diversidad interna" son ontologías completamente diferentes; nociones holistas de la persona, la salud psíquica, física, espiritual y social que son absolutamente divergentes de las institucionalizadas, y que por lo tanto van mucho más allá de meras reinterpretaciones o reapropiaciones de símbolos y conceptos católicos. La idea de muchos catolicismos, sustentada en una relevancia desmedida y naturalizada brindada a las identificaciones (que como dije no suelen tener demasiada relevancia personal o colectiva, apenas social en el momento en que el encuestador la pregunta), es, como dicen los norteamericanos, tan solo una forma de "explain away" la diversidad religiosa de nuestras sociedades. ${ }^{8}$

Resumiendo: ¿por qué no podemos ver la diversidad religiosa? Porque buscamos la religión principalmente o únicamente en grupos estables que producen identificaciones religiosas diferenciales, y no en la enorme variedad de agrupaciones de todo tipo que postulan cuáles son los seres suprahumanos con los que debemos vincularnos y de qué maneras. ${ }^{9}$ Así, barremos y ocultamos

${ }^{8}$ Que un censo o encuesta brinde la información de que un $90 \%$ de la población es católica significa que ese porcentaje ha optado, ante una pregunta puntual sobre afiliación religiosa, por la identidad social de católico. Este acto puntual de identificación ante una pregunta concreta y no muy frecuente en la vida de una persona- no nos dice nada sobre qué lugar ocupa el ser "católico" en su estructura de compromisos identitarios y si esta identificación tiene alguna relevancia para su identidad personal (su self). Que una persona haya optado por la identidad social de católico tampoco indica si se siente parte de un "nosotros" católico con la suficiente intensidad como para actuar colectivamente en beneficio de este grupo ("católico" como identidad colectiva). Discuto esta conceptualización de las identificaciones en Frigerio (2007, 2018).

${ }^{9}$ En un trabajo reciente, en un intento por trascender la búsqueda casi exclusiva de religión en organizaciones del tipo iglesia o secta, argumenté por la necesidad de examinar espacios de 
debajo de la alfombra de la "homogeneidad religiosa" una cantidad de prácticas religiosas, por considerarlas apenas manifestaciones de esoterismo, curanderismo, religiosidad popular o espiritualidad. De esta manera, lo queramos o no, lo sepamos o no, estamos contribuyendo a la perpetuación de visiones normativas de la religión y participando del juego de descalificación de determinadas prácticas sociales.

\section{Sesgos eclesiocéntricos y una idea muy restricta del campo religioso por detrás de estas divisiones}

Esta división de campos de incumbencia relativos a la religión o a lo religioso en nuestras ciencias sociales revela la prevalencia, mayormente implícita, de sesgos eclesiocéntricos en nuestro análisis y una conceptualización muy restringida de la idea bourdieuana de "campo religioso".

Nuestra visualización de quiénes serían los agentes y agrupaciones que componen el campo religioso está indudablemente influenciada por las herramientas teóricas que utilizamos para el estudio de la religión, las que están modeladas en, o provienen de, contextos cristianos (Bell 2006; Cannel, 2005; Frigerio, 2020; McGuire 2007). En Latinoamérica ha sido Parker (2010) quien probablemente más claramente ha denunciado el perfil eclesiocéntrico y occidentocéntrico de la sociología de la religión, cuyas categorías analíticas están demasiado atadas a formas institucionales derivadas de la historia europea y no necesariamente aplicables universalmente y tampoco, acríticamente, a la realidad latinoamericana. ${ }^{10}$

Afirma este autor chileno:

sociabilidad religiosa y muy diferentes tipos de organizaciones de movimientos religiosos de manera transversal a estas subáreas de conocimiento: en la espiritualidad contemporánea (o la Nueva Era, que es donde más se han reconocido), en el campo de los curanderos, del esoterismo, de la religiosidad popular e incluso en las religiones establecidas que muestran una diversidad interna de agrupaciones que supera en mucho a las congregaciones semanales estables más obvias (Frigerio, 2020).

${ }^{10}$ Semán (2001) también nos ha advertido acerca del modernocentrismo implícito en nuestras perspectivas de análisis (ver Frigerio, 2020). 
detrás de las estadísticas religiosas clásicas se encubre un enfoque que no sólo es empiricista y cuantitativo, sino además eclesiocéntrico y occidentocéntrico porque tiende implícitamente a identificar a "la religión" con su expresión eclesial como se ha dado en la historia del Occidente cristiano (...) la ética religiosa y la devoción individual o colectiva extraeclesial generalmente quedan fuera del foco del análisis clásico, orientado por sesgos eclesiocéntricos. De esta manera, la sociología concede a la teología implícita en este tipo de enfoques y pierde su capacidad de comprensión y explicación. (Parker, 2010, pp. 51$52)$.

A continuación, muestra luego cómo en las teorías de Troeltsch, Weber, Durkheim y Mauss, la iglesia continúa siendo el parámetro por el cual, de manera muy explícita o bastante implícita y velada, voluntariamente o no, según el caso, se sigue definiendo el fenómeno religioso en contraposición a otros como la magia. Este modelo y estas categorizaciones siguen guiando y moldeando nuestro análisis hasta el día de hoy y explican nuestra conformación del área de la religión en contraposición a las otras áreas que he señalado antes (ver también Frigerio, 2018, 2020).

Las divisiones muy tajantes que se establecen entre religión, espiritualidad, religiosidad popular, esoterismo y curanderismo -categorías que por otro lado, reitero, están siempre muy pobremente definidas- parecen responder también a la idea de que constituirían campos sociales específicos a la manera de Bourdieu (o a la manera local en que se entiende el concepto de este autor), en una visión de estos que los asemeja a las esferas diferenciadas de valor de Weber. Para los estudios especializados, cada una de las subáreas que mencioné más arriba funcionaría de manera prácticamente autónoma con reglas y características propias y con agentes sociales específicos $-\mathrm{y}$ por ello resultaría conveniente abordarlas por separado y con instrumentos teórico-conceptuales apropiados para cada una.

Las críticas a la utilización local de la idea de campo religioso han sido varias, aunque no suficientemente atendidas. Martínez (2013) ha señalado que localmente este concepto "se ha convertido, en los textos de muchos 
especialistas, en una especie de 'comodín lingüístico' (....) sin por eso ser utilizado como un instrumento de análisis" (p. 91). Siguiendo el camino de sus pares franceses, muchos académicos locales parecen asimilar la idea de campo a la de esferas diferenciadas de valor de Weber (Martínez, 2013):

$\mathrm{Si}$ entendemos los campos como espacios rígidamente delimitados, si no advertimos los instrumentos conceptuales que nos permiten describir las transposiciones de capital, si asimilamos demasiado la diversidad de campos a las teorías clásicas de la secularización como separación de esferas, el modelo analítico pierde capacidad de "deformación" (Bachelard 1996: 91) para adaptarse a describir procesos de transformación como los que vivimos en América Latina. Aquella no nos parece ser la perspectiva bourdieana (como se ve en La disolución de lo religioso, 1988), o, en todo caso, no la que pueda ser más fecunda en América Latina (...) (Martínez, 2013, p. 96).

Semán (2002) también abogó por la conveniencia de utilizar la más reciente conceptualización de campo religioso que hizo Bourdieu (1988) por sobre la clásica y más conocida (Bourdieu, 1971). En su crítica a la separación demasiado tajante que se suele hacer entre literatura y religión (tanto desde los estudios sobre literatura como desde los estudios sobre religión), señala:

En términos generales, esta posibilidad" (la de que la literatura de masas pueda ser un vector del campo religioso) "puede basarse en la afirmación de Bourdieu (1988: 105) sobre la disolución del campo religioso en el sentido clásico de un campo de conflicto entre iglesias en torno a bienes de salvación (lo que ya supone la naturalización de algunos bienes religiosos cuya presencia está hoy declinando). Esta noción debe ser substituida por la concepción de campo religioso como un campo de disputa al respecto de los límites y, especialmente, de la propia definición de religioso entre agentes de los campos más variados. (Semán, 2002, p. 268; énfasis y traducción míos). ${ }^{11}$

${ }^{11}$ En un trabajo posterior, Semán (2013) vuelve a enfatizar la necesidad de considerar un campo religioso heterogeneizado, basado en la autocrítica que realiza Bourdieu en La disolución de lo religioso (1988): "En el campo religioso heterogeneizado, lejos de ocurrir lo 
Como suele suceder con la definición de religión de Geertz (1973), la de campo religioso de Bourdieu es frecuentemente ofrecida al principio de los trabajos sin una aplicación reflexiva al material que será analizado $-\mathrm{y}$ sin demasiada preocupación por el cristianocentrismo que la propia noción de bienes de salvación impone. ${ }^{12}$ También, sin prestar demasiada atención a la necesidad de especificar, en los análisis de quienes serían los que delimitarían el alcance del "campo religioso", si lo harían determinados actores sociales socialmente legitimados o los estudiosos. Si se piensa que esta delimitación la realizan los actores sociales, sería conveniente -para no brindar una versión naturalizada y normativa de la religión- especificar cuáles son las asimetrías de poder que les permiten definirlo. Asimismo, sería necesario reflexionar también acerca de cuál sería la complicidad de los estudiosos que reafirman esa construcción sin ponerla en duda o ratificar que es, en efecto, un acto de ejercicio de poder social. ${ }^{13}$

que describe Bourdieu en 1971, no compiten tan sólo distintas fórmulas de comprender la eucaristía, de administrar la salvación. En el campo religioso se confrontan concepciones que tienen como bien religioso a la salvación, pero también la sanidad, la prosperidad, etc. En el campo religioso heterogeneizado compiten el consuelo de la cruz, la promesa de sanación, las búsquedas interiores a través de la dieta y los ejercicios respiratorios (o sea religiones que afirman la existencia del algo así como lo espiritual y otras que rechazan esa categoría o, al menos, la forma de dividirla de lo físico y lo psicológico).(...) Pero además el campo religioso heterogeneizado es multidimensional y debe distinguirse lo que ocurre en sus elites de lo que ocurre en sus bases" (Semán, 2013, pp. 73-74).

${ }^{12}$ Luego de señalar que el concepto es utilizado mayormente como un comodín linguistico, Martínez nota que "[s]alvo excepciones, es una expresión que usamos rápidamente en los preámbulos de nuestros artículos para continuar luego estudiando, desde distintos marcos téoricos, los aspectos de la diversidad religiosa sobre la que hacemos foco" (Martínez, 2013, p. 91). Similarmente, Semán (2013) afirma: "La noción de campo religioso ha sido frecuentemente utilizada hasta ser una referencia convencional y obligada" (p. 72).

${ }^{13}$ Otra crítica latinoamericana relevante es la de Suárez (2006), quien también reconoce el carácter local y situado de la idea de campo de Bourdieu y advierte que: "Pensando desde la experiencia latinoamericana, es evidente que se debe realizar una relectura a la lectura de Bourdieu. Por un lado, el propio autor afirma que la concentración de capital religioso y el 'monopolio de hecho casi perfecto' sucedió en el catolicismo medieval (Bourdieu 1971, 326). En sentido contrario a lo sucedido en Europa, en América Latina las formas de administración de los bienes de salvación han estado marcadas por figuras paraeclesiales que -de manera abierta o disimulada, con tensiones o acuerdos-, han cuestionado la legitimidad de los agentes burocráticamente designados para tal función al interior del catolicismo. Por ejemplo las mayordomías en México o los 'prestes' en Bolivia dibujan un campo religioso compuesto no sólo por sacerdotes, profetas, magos y laicos sino, además y preponderantemente, por agentes intermedios de manipulación de lo sagrado, con amplios grados de autonomía y legitimidad 
A continuación brindaré un par de ejemplos para ilustrar cómo esta división naturalizada y reificada de subáreas de incumbencia dentro del estudio de lo religioso nos ha impedido comprender e interpretar adecuadamente las características y consecuencias de una serie de presencias indicadoras de la relevancia de la diversidad religiosa en el pasado argentino, supuestamente "monopolizado" por el catolicismo.

\section{Anomalías durante el monopolio católico}

Siguiendo las pistas teóricas de lo que denomino un paradigma de la diversidad religiosa -alternativo al actual dominante catolicéntrico del monopolio religioso-, y aprovechando los cada vez más numerosos estudios sobre curanderos realizados desde la historia y desde la antropología, he propuesto la necesidad de considerarlos (o al menos, a buen número de ellos) como parte de la economía religiosa de nuestras sociedades (Frigerio, 2020, en prensa). Muy frecuentemente, estos/as especialistas tienen símbolos religiosos o altares de manera muy visible en los lugares donde brindan consultas y recetan trabajos, oraciones o comportamientos relacionados con santos $\mathrm{u}$ otros seres poderosos que promueven nuevos significados y maneras de relacionarse con estos seres suprahumanos. Aunque no proponen identificaciones religiosas, ciertamente fomentan interpretaciones heterodoxas de símbolos religiosos provenientes de las iglesias instituidas o de religiones minoritarias que acarrean modificaciones de las creencias y prácticas religiosas de sus consultantes. ${ }^{14}$

tanto frente los consumidores como frente a autoridades burocráticas. Por otro lado, el modelo teórico de Bourdieu puede encontrar dificultades para explicar formas religiosas cuya principal característica no es la pertenencia a un determinado campo sino que más bien se concentran en experiencias esporádicas y transitorias, sin exigencia de continuidad regular ni adscripción militante, con pocos grados de vinculación institucional; por ejemplo el New Age, las devociones angélicas, etcétera" (p. 24).

${ }^{14}$ Más específicamente, he sugerido que: a) pluralizan el espectro de seres suprahumanos con los cuales sus consultantes pueden relacionarse (añadiendo, por ejemplo, al Gauchito Gil a Iemanjá o a la Pomba Gira de las religiones afrobrasileras, aunque descontextualizadas de las cosmovisiones originales); b) rejerarquizan los seres suprahumanos católicos (le pueden otorgar más importancia a San Jorge o a San Expedito o a cualquier santa de su preferencia sobre 


\section{La Madre María}

En Argentina, el ejemplo más patente de invisibilización e incomprensión académica de estos agentes mágico-religiosos es el de la Madre María, considerada en su momento, y aún actualmente, como la más famosa "curandera" del país. Sin embargo, sus prácticas "sanadoras" eran complementarias o secundarias en relación con sus enseñanzas religiosas, que transmitía a cientos o miles de devotos y en las cuales proponía una relectura del mensaje bíblico cristiano. Para los estudios académicos, sin embargo, lo único significativo parecen ser sus actividades sanadoras y no el mensaje obviamente religioso que transmitió.

Luego de dos experiencias extraordinarias que le indicaron un camino religioso, la Madre María predicó una versión propia del mensaje cristiano, con tintes milenaristas, que atrajo multitudes a su casa en la ciudad de Buenos Aires, y luego en la localidad de Turdera, en el Gran Buenos Aires. ${ }^{15}$ Por carecer de estudios específicos, no sabemos bien si su popularidad se debió más a su fama de sanadora o a su mensaje religioso -o a una combinación variable de ambos. Los libros de sus discípulos priorizan y resaltan su mensaje espiritual. Los medios de la época enfatizan en la sanación -lo que le valió un proceso por ejercicio ilegal de la medicina en 1911 del que salió airosa en 1912- e ignoran su doctrina religiosa. Su fallecimiento en 1928 no impidió que su influencia mágico-religiosa creciera más aún. Miles de devotos continuaron visitando su tumba en busca de milagros, y en 1944 por suscripción popular se le erigió un monumento en la Chacarita. Al lado de su tumba, un pedestal más

Jesucristo o la Virgen); c) promueven nuevas maneras de relacionarse con ellos; d) generan o reconfirman nociones holistas de la persona, que vinculan los planos físico-psicológicoespiritual-social y hasta cósmico en la búsqueda de la salud o el bienestar de sus consultantes; e) validan o incentivan visiones encantadas de la realidad; y f) confirman la existencia de seres y energías negativas que los consultantes deben evitar o combatir (Frigerio, en prensa).

${ }^{15}$ Un primer episodio significativo fue su visita al famoso sanador gaucho de Pergamino Pancho Sierra, quien se dice que la sanó de un mal incurable y le pronosticó: "No tendrás más hijos de tu carne, pero tendrás miles de hijos espirituales". A partir de allí, ella siempre reivindicaría a Pancho Sierra como su maestro. Un segundo episodio que originó su posterior prédica espiritual, fue una experiencia de casi muerte, un ayuno intenso y una noche entera de rezo. 
alto que una persona sostiene una estatua tamaño natural de la Madre María, con la mano derecha levantada y su dedo índice señalando el cielo. Hasta el día de hoy su mausoleo es visitado por centenares de personas que le hacen todo tipo de pedidos en el día de su natalicio y de su muerte -pero también en cualquier momento en que lo necesiten. Junto con la de Carlos Gardel, su estatua es quizás la única en ese cementerio que siempre cuenta con flores frescas.

En la mayor parte de los sorprendentemente pocos escritos (más o menos) académicos sobre su persona, es considerada el ejemplo paradigmático de la curandera o sanadora argentina. Una foto suya ilustra la tapa del libro Los manosantas de Horvath (1977), y una de su tumba y monumento están en la tapa del libro de Hugo Ratier (1972), La medicina popular-ambos clásicos de estos temas durante la década de su aparición y la siguiente. Su nombre también aparece en el título del libro de Raúl Garelli (1966), Brujos y curanderos: de Pancho Sierra a la Madre María. Hay apenas dos trabajos exclusivos (más ensayísticos que académicos) sobre su persona: un capítulo de Leone (1992) en un libro titulado Ocultismo y espiritismo en la Argentina (cuya tapa también está ilustrada con la foto de su tumba y el monumento) y un artículo en la famosa revista de difusión Todo es Historia (Maurizi, 1968). Además, tiene una entrada en el libro clásico de Coluccio (1986) sobre religiosidad popular y menciones en el libro de Bianchi (2004) sobre historia de las minorías religiosas (encuadrada como religión popular) y en el de Bubello (2010), que relata la historia del esoterismo en la Argentina. Aparecen también algunas referencias a su persona en algunos textos sobre curanderos (Dahhur, 2013). ${ }^{16}$ Los tres templos que reivindican seguir sus enseñanzas figuran en la Guía de la diversidad religiosa de Buenos Aires (vol. 2) (Forni, Mallimaci y Cárdenas, 2008) bajo el acápite de religiosidad popular.

Académicamente, entonces, su figura ha sido encuadrada principalmente dentro del curanderismo (Dahhur, 2013; Garelli, 1966; Horvath 1977; Ratier,

${ }^{16}$ Figura también entre las "psicoterapias populares" de Alfredo Moffat en su libro Psicoterapia del oprimido (1974). Esta obra tuvo varias reediciones, la sexta en 1997 ya con el nombre de Socioterapia para sectores marginados: terapia comunitaria para grupos de riesgo. 
1972), del esoterismo (Bubello, 2010; Santamaría, 1992) y/o dentro de la incumbencia de la religión popular (Bianchi, 2004; Forni et al., 2008). Estas referencias y encuadres contrastan radicalmente con los títulos de los libros escritos por sus discípulos y seguidores que enfatizan el aspecto religioso y cristiano (obviamente, nada de popular) de sus enseñanzas (Cueto, 1921, 1926, 1928; Forte, 1944; García Risso, 2010). La naturaleza principalmente religiosa del culto también se evidencia por el hecho de que sus seguidores han establecido tres iglesias o templos que, con sus sucursales, están inscriptos en el Registro de Cultos No Católicos de la Nación. $\underline{17}$

La multiplicidad de encuadres interpretativos de su figura no está solamente ligada a una posible multidimensionalidad del fenómeno, sino, principalmente, a construcciones flojas cuando no incoherentes del objeto de estudio. ¿Acaso su creencia en la reencarnación avala su inclusión en esoterismos, cuando el resto de su mensaje es indudablemente cristiano y su prédica siempre fue pública y abierta?, ¿o que su mentor Pancho Sierra haya sido en oportunidades calificado como espiritista (que aparentemente no lo era, aunque ciertamente los espiritistas querían reclamarlo como uno de los suyos) justifica incluirla dentro de los espiritismos sui generis del país? (Ludueña, 2007). Si bien la devoción actual que se desarrolla alrededor de su tumba puede ser considerado un caso de religiosidad popular (con innegables semejanzas a otras devociones populares como la Difunta Correa o el Gauchito Gil), la actividad de los templos que reivindican su mensaje y enseñanzas no necesariamente deberían incluirse en esa categoría -no, al menos, sin estudios específicos sobre ellos que ciertamente no tenemos, y sin una especificación conceptual de la lógica de la aplicación de esta clasificación, de la cual también carecemos.

${ }^{17}$ Varias décadas luego de su muerte y durante mucho tiempo la Madre María también formó parte del panteón de seres suprahumanos invocados por el culto cristiano Irma de Maresco, del Hermano Miguel, quien durante un largo período predicó al pie de su monumento en la Chacarita, y se atribuía el haber logrado hacer quitar su imagen de la sala de "curanderismo" del Museo Histórico de la Policía Federal. Problemas con los herederos de la Madre María hicieron que actualmente su figura fuera reemplazada en el "Triángulo Espiritual" por el de Gauchito Gil (junto con Pancho Sierra y la Hermana Irma, la madre del Hermano Miguel). 
Más allá del carácter multifacético que la figura de la Madre María pueda haber tenido (profeta-sanadora-líder carismática-santa popular), lo cierto es que en vida, por el tenor de sus enseñanzas y actividades, la Madre María y sus seguidores fueron más un fenómeno religioso que curanderil o esotérico o mágico. Haberle negado sistemáticamente esta condición parece mostrar que los científicos sociales estamos continuando los prejuicios sociales de la época que en cualquier curandera veían, de manera irónica y descalificatoria, a la Madre María.

\section{El pastor Tommy Hicks}

Otro ejemplo revelador de los límites de los paradigmas interpretativos vigentes, de la necesidad de una visión más amplia y complejizada del campo religioso y de las interacciones entre (y/o integralidad de) las diferentes subáreas de estudio es el del pastor pentecostal norteamericano Tommy Hicks, cuyas campañas de sanidad en estadios de fútbol causaron un enorme impacto en la sociedad argentina en 1954. Como sucedió con la Madre María, es interesante en este caso la poca atención académica brindada al fenómeno. Aún más revelador de nuestros prejuicios académicos es el tenor de las explicaciones -mayormente políticas- que se han avanzado para comprender su éxito en un momento en que las iglesias pentecostales no tenían la fuerte presencia que hoy, medio siglo más tarde, tienen en el país.

Siendo que es un fenómeno que atañe a grupos tradicionalmente considerados como parte del campo religioso -ya que los pentecostales crean y exigen nítidas identificaciones religiosas-, no hay en este caso dudas respecto de en qué subárea ubicarlo. No se lo analizó desde encuadres de esoterismo, curanderismo o religiosidad popular ni de antropología de la salud; aunque en este caso, paradójicamente, algunos de los insights desarrollados en estos campos sí serían de utilidad -pero como el evento es catalogado como religioso, no se aplicaron. Otro motivo por el cual probablemente no se le prestó mucha atención académica es porque pese a la cantidad de gente que movilizó la campaña durante dos meses en 1954 (las estimaciones llegan hasta seis millones de personas) no produjo demasiados resultados significativos en 
términos de conversiones religiosas, vale decir, no produjo cambios visibles en las identificaciones religiosas de quienes acudieron -un resultado considerado necesario por los académicos para darle relevancia y carnadura sociológica al evento.

Hicks llegó al país en un momento en que las relaciones del entonces presidente Juan Domingo Perón con la Iglesia eran tensas. Logró una entrevista con el entonces presidente y su visto bueno para realizar las campañas y anunciarlas por los medios de comunicación. Una foto de ambos testimoniando el encuentro salió en varios medios y produjo un gran impacto social (según algunas versiones la reunión fue posible porque había sanado a alguien del entorno de Perón, según otras porque este quería reemplazar el apoyo eclesiástico católico por el de otras confesiones como los espiritistas y los pentecostales). La campaña comenzó con poco público en el estadio de Atlanta, pero con el correr de los días y los comentarios boca a boca la concurrencia comenzó a aumentar y fue necesario trasladarla al estadio de Huracán, un sitio mayor con capacidad para albergar a 110 mil personas sentadas. La duración inicial de 15 días de la campaña se cuadruplicó. La Policía Federal calculó que un total de seis millones de personas pasaron por los estadios a recibir la sanidad divina, con cuatrocientas mil en la última noche (con muchas siguiendo el evento desde fuera del estadio).

En los relatos evangélicos de esos días abundan los milagros y la descripción de la conmoción social que el pastor norteamericano causó en la ciudad. Los recuerdos de los pastores mencionan medios de transporte desbordados por la cantidad de gente que iba a las reuniones, el envío de camiones cada día luego de las reuniones por el gobierno de la ciudad para juntar las muletas y sillas de ruedas que dejaban los sanados, que al pastor Hicks le tomaba una o dos horas entrar al estadio por la multitud que lo aguardaba, y que en ocasiones debía salir vestido de mujer del hotel para eludir a quienes clamaban por su ayuda (Zielicke, 2012). Los analistas locales (Míguez, 2002; Saracco, 1989; Wynarczyk, 2009) señalan que todo este fervor no pudo ser canalizado por las iglesias pentecostales para su crecimiento porque 
no tenían la estructura necesaria para hacerlo. Zielicke (2012), que presta más atención a las opiniones de pastores pentecostales de la época, señala que sí tuvo efectos, aunque no inmediatos, al menos mediatos para el crecimiento evangélico.

En los únicos dos artículos académicos locales dedicados exclusivamente a la visita de Hicks, las explicaciones que se avanzan para comprender su éxito son de cuño político. Saracco (1992) explica la masiva concurrencia a los actos de Hicks apelando a la idea de sustitución de liderazgo carismático: la debilidad de Perón en ese momento causó un vacío de carisma que el pastor norteamericano vino a llenar:

(...) en cada situación crítica el líder carismático necesita revalidar la vigencia de sus dotes. Al mismo tiempo, en la crisis, la masa necesita de un líder en el cual poder depositar sus esperanzas. Hicks cumplió, a nivel de conciencia social, un rol supletorio del liderazgo carismático en crisis de Perón [...] En abril de 1954, la masa necesitaba un Tommy Hicks. (Saracco cit. en Wynarczyk, 2009, p. 6).

Wynarczyk (2009) concuerda parcialmente con el argumento, pero propone también tomar en cuenta "la específica agencia del presidente de la nación en lo tocante al campo religioso" (p. 12). Deteriorada su relación con la Iglesia católica, sin el apoyo carismático de Evita a su lado, el presidente argentino buscó seducir a otras iglesias, entre ellas el pentecostalismo y los espiritistas. $^{18}$

En este caso, al revés de lo que sucedió con el de la Madre María remoción de un fenómeno religioso del área de la religión hacia las del curanderismo, el esoterismo o la religiosidad popular-, el fenómeno es

18 Otros estudiosos locales del tema, en trabajos más generales sobre la relación entre pentecostalismo y política, se permiten dudar de la inmediata identificación e intercambio que se puede producir entre capitales políticos y religiosos (Algranti, 2010; Carbonelli, 2011b; Semán, 2013), pero no dejan de ver afinidades entre peronismo y pentecostalismo sobre la base de "la afinidad electiva establecida en el recíproco anclaje entre los sectores populares (...), y la mutua utilización de un formato discursivo populista que habilita decodificaciones sucesivas en uno y otro sentido" (Carbonelli, 2011a, p. 109).

Revista Cultura \& Religión Vol. XV, 2021 Nº 1 (enero-junio) 
interpretado como religioso y como tal se le aplican las interpretaciones consideradas más relevantes para esa área. En el caso del estudio de la religión en Argentina, la dimensión política ha sido siempre notablemente sobrevalorada -en un intento por jerarquizar y legitimar la sociología de la religión de acuerdo con los intereses y las variables consideradas relevantes dentro de la disciplina de la sociología (ver Semán, 2013, para un análisis más complejo en este sentido). Las creencias religiosas parecen ser dignas de estudio solo si impactan en el campo de la acción política (considerada restringidamente como partidaria, o más ampliamente, como acción en la esfera pública en pos de determinados resultados sociales). Las creencias y prácticas religiosas en sí, o su impacto en otras dimensiones de lo social (salud, sociabilidad, ocio, subjetividad) no parecen tener tanta relevancia dentro de la sociología de la religión (basta ver la cantidad de estudios dedicados a los distintos temas).

Se descarta para este caso, entonces, la evidencia acumulada en las otras áreas (como la religiosidad popular, la antropología de la salud) que ayudaría a comprender la fácil receptividad social al discurso de sanación de Hicks, aun en tiempos de monopolio católico; la vigencia de cosmovisiones encantadas, de sensibilidades cosmológicas y de nociones holistas de la persona que ven normal y deseable la intervención de seres suprahumanos en problemas cotidianos y de salud (Semán, 2001).

Existe en la ciudad de Buenos Aires una larga y rica tradición de agentes mágico-religiosos (des)calificados como curanderos (Bubello, 2008) que, como la Madre María, proponían mensajes religiosos, generalmente lecturas heterodoxas del cristianismo y que también postulaban la intervención de seres suprahumanos en sus curaciones -ya fuera porque se consideraban sus emisarios o los beneficiarios de sus dones divinos (Carozzi y Frigerio, 1992; Frigerio, 1999, en prensa). Teniendo en cuenta esta rica y centenaria tradición, siempre considerada irrelevante para el campo religioso, no es de extrañar la posibilidad de que Hicks fuera visto por quienes acudían a sus ceremonias como uno más en una larga serie de sanadores religiosos; es decir, que resonara 
perfectamente con un contexto social y de tradición cultural de larga data. ${ }^{19} \mathrm{Su}$ masividad extraordinaria -en relación con otros agentes mágico religiosos anteriores- se puede explicar por el hecho de que durante un breve período la conflictiva relación de Perón con la Iglesia católica produjo un breve interregno de desregulación social y gubernamental de la "economía religiosa" (Frigerio y Wynarczyk, 2008), que permitió la libre expresión y ocupación del espacio público por otros grupos religiosos. Para este caso específico, esta desregulación incidió en la posibilidad de realizar grandes concentraciones (antes prohibidas o desincentivadas) y en que los medios de comunicación transmitieran y magnificaran su impacto. ${ }^{20} \mathrm{Su}$ condición de extranjero realizando una visita al país también debe haber ayudado para acrecentar su extraordinariedad.

\section{Conclusiones}

En este trabajo se ha argumentado que en los estudios de la religión predomina una delimitación excesivamente restricta del campo religioso, el cual posee límites borrosos y superposiciones con otros campos vecinos pobremente definidos (espiritualidad, esoterismo, religiosidad popular, salud), lo que lleva a dejar prácticamente por fuera de la producción y transmisión de la religión a las industrias culturales, los medios de comunicación y las redes sociales. Esto se debe principalmente a la utilización de perspectivas teóricas que son simultáneamente catolicocéntricas, modernocéntricas y eclesiocéntricas, y a la aplicación imprecisa -en citas prácticamente obligadas, más que analíticamente fundadas- del concepto de "campo religioso" de Bourdieu. Mayormente al

\footnotetext{
${ }^{19}$ Míguez (2002) también considera esta posibilidad (ver, asimismo, Semán, 2013).

${ }^{20}$ Una lectura cuidadosa de raccontos de actividades de curanderos - en textos académicos y en medios de la época- sugiere que en muchos casos conocidos de "Hermanos" (una denominación corriente para curanderos portadores de mensaje religioso e intenciones de formar algún tipo de comunidad religiosa), su poder de convocatoria era mayor del habitualmente admitido en nuestros estudios eclesiocéntricos. Al revés de Hicks, sin embargo, estos contaban con la condena y el no apoyo o la neutralidad, al menos, de los medios de comunicación y la persecución -y no colaboración, como en el caso del pastor norteamericano, de la policía.
} 
hacerlo se toma en cuenta su artículo de 1971 que el propio sociólogo francés ha admitido reflejaba un contexto muy específico y situado histórica y geográficamente en Francia, al tiempo que se ignora su autocrítica y su concepción mucho más realista y actual de un campo religioso ampliado o "heterogeneizado"(como lo denomina Semán, 2013) en La disolución de lo religioso (Bourdieu, 1988).

La diferenciación arbitraria en subáreas de especialización e incumbencia (religión, espiritualidad, esoterismo, religiosidad popular, salud) produce compartimientos naturalizados casi estancos que brindan una visión muy empobrecida y restringida de la "diversidad religiosa", ya que esta es ubicada como tan solo una parte muy pequeña del campo religioso: la que no corresponde al catolicismo y en la cual hay grupos "otros", minorías religiosas que responden mayormente al tipo "iglesia" o "secta" y producen identificaciones religiosas (Frigerio, 2020).

Fragmentamos así demasiado artificialmente nuestro objeto de estudio, $\mathrm{y}$ esencializamos las diferencias entre actividades y actores que en la vida cotidiana de los sujetos están muy entrelazados. Ocultamos, sobre todo, una gran cantidad de creación y práctica de diversidad religiosa, que sucede en todas estas áreas colindantes con el campo religioso (social y académicamente legitimado), en las cuales también se postulan nociones acerca de los seres suprahumanos con los cuales podemos entablar relaciones, y se proponen asimismo las mejores maneras de hacerlo.

La división en subáreas temáticas mayormente estancas tiene otras consecuencias negativas: se forman ámbitos de especialización académica con poca comunicación entre estudiosos, lo que dificulta interpretaciones abarcativas e integradoras de las subáreas, Por el contrario, cada subárea de especialización desarrolla sus propias perspectivas teóricas, sus temas principales de estudio, sus preguntas de investigación y las bibliografías relevantes -lo que los lleva a trabajar con supuestos teóricos y protagonistas sociales muy específicos. 
En este artículo se ha mostrado con dos ejemplos empíricos cómo, sobre la base de estas divisiones arbitrarias - definidas de manera muy poco precisa-, se dificulta nuestra comprensión de la diversidad religiosa en el pasado argentino, supuestamente monopolizado por el catolicismo. En el caso de la Madre María, se invisibiliza su actividad y mensaje religiosos y se la desplaza irreflexivamente hacia las subáreas del curanderismo o esoterismo. Para el caso de Tommy Hicks, ante la extrañeza por su convocatoria masiva se avanzan argumentos políticos, afines al área de estudiosos de la religión, y se ignora la resonancia de sus prácticas con una larga tradición de sanadores y curanderos de todo tipo que participaban de las visiones encantadas de buena parte de la población de la ciudad. Por ser anomalías en un pasado supuestamente monopolizado por el catolicismo, poco se los ha estudiado, y mucho menos de manera conjunta.

Se podrían encontrar numerosos ejemplos más, del pasado y aún del presente, que mostrarían qué tan limitada y catolicocéntrica es nuestra percepción de "lo religioso", y cuán normativa y alineada con los agentes religiosos poderosos y socialmente legitimados continúa siendo nuestra práctica académica.

\section{Referencias bibliográficas}

Algranti, J. (2010). Política y religión en los márgenes. Nuevas formas de participación social de las mega-iglesias evangélicas en la Argentina. Buenos Aires: Ediciones Ciccus.

Algranti, J. (2013). La industria del creer. Sociología de las mercancías religiosas. Buenos Aires: Biblos.

Bell, C. (2006). Paradigms behind (and before) the modern concept of religion. History and Theory, 45(4), 27-46.

Bianchi, S. (2004). Historia de las religiones en Argentina: las minorías religiosas. Buenos Aires: Sudamericana. 
Bourdieu, P. (1971). Génèse et structure du champ religieux. Revue Française de Sociologie, 12(3), 295-334.

Bourdieu, P. (1988). La disolución de lo religioso. En P. Bourdieu (comp.), Cosas dichas (pp. 102-107). Buenos Aires: Gedisa.

Bubello, J. P. (2008). Caras y caretas y "esa infame comparsa de malas mujeres..." Notas sobre la estigmatización cultural de las prácticas de curanderismo, hechicería y adivinación durante el Centenario (Buenos Aires, 1900-1910). En M. Bravo, F. Gil Lozano y V. Pita (comps.), Historias de luchas, resistencias y representaciones: mujeres en la Argentina, siglos XIX y XX (pp. 335-360). Tucumán: EDUNT.

Bubello, J. P. (2010). Historia del esoterismo en la Argentina: prácticas, representaciones y persecuciones de curanderos, espiritistas, astrólogos y otros esoteristas. Buenos Aires: Biblos.

Carbonelli, M. (2011a). Una lectura sobre la producción científica acerca de la participación política evangélica en la vida democrática argentina (1983-2010). Cultura \& Religión, 5(2), 96-116.

Carbonelli, M. (2011b). Mediaciones con lo político. Análisis de la participación de actores evangélicos en partidos políticos en el AMBA. (Tesis de maestría en Ciencia Política), IDAES/Universidad Nacional de San Martín, Buenos Aires, Argentina.

Carozzi, M. J. y Frigerio, A. (1992). Mamãe Oxum y la Madre María: santos, curanderos y religiones afro-brasileñas en Buenos Aires. Afro-Asia, 15, 71-85.

Coluccio, F. (1986). Cultos y canonizaciones populares de Argentina. Buenos Aires: Ediciones Del Sol.

Cueto, E. (1921). La Madre María y su doctrina. Buenos Aires: Talleres Preusche.

Cueto, E. (1926). La fe en Dios y la religión de Cristo. La doctrina de la Madre María. Buenos Aires: Talleres Gasperini.

Cueto, E. (1928). La religión cristiana y la Madre María. Buenos Aires: El Libro. 
Dahhur, A. (2013). Ataques a curanderos. La medicina y su lucha por el control social de la población en los primeros años del siglo XX. XIV Jornadas Interescuelas/Departamento de Historia de la Facultad de Filosofía y Letras, Universidad Nacional de Cuyo, Mendoza, 2 al 5 de octubre. Recuperado de https://cdsa.aacademica.org/000-010/530.pdf

Forni, F., Mallimaci, F. y Cárdenas, L. (2008). Guía de la diversidad religiosa de Buenos Aires. Tomo 2. Buenos Aires: Biblos.

Forte, C. (1944). La religión de Dios por la Madre: Escuela de la Regeneración Espiritual. Buenos Aires: Talleres Cersósimo.

Frigerio, A. (1993). La invasión de las sectas: el debate sobre nuevos movimientos religiosos en los medios de comunicación en Argentina. Sociedad y Religión, (10), 24-51.

Frigerio, A. (1999). El futuro de las religiones mágicas en Latinoamérica. Ciencias Sociales y Religión/Ciências Sociais e Religião, (1), 51-88.

Frigerio, A. (2000). No será una secta?: imágenes de problemas sociales en programas televisivos de ficción. Cuadernos de Antropología Social, (11), 387-404.

Frigerio, A. (2007). Repensando el monopolio religioso del catolicismo en la Argentina. En M. J. Carozzi y C. Ceriani (eds.), Ciencias sociales y religión en América Latina (pp. 61-86). Buenos Aires: BIBLOS.

Frigerio, A. (2013). Lógicas y límites de la apropiación New Age: donde se detiene el sincretismo. En R. De La Torre, C. G. Zúñiga y N. J. Huet (comps.), Variaciones y apropiaciones latinoamericanas del New Age (pp. 47-70). México, D.F.: Casa Chata/CIESAS/ColJal.

Frigerio, A. (2016). La ¿'nueva’? espiritualidad: ontología, epistemología y sociología de un concepto controvertido. Ciencias Sociales y Religión/ CiênciasSociais e Religião, (24), 209-231.

Frigerio, A. (2018). ¿Por qué no podemos ver la diversidad religiosa?: cuestionando el paradigma católico-céntrico en el estudio de la religión en Latinoamérica. Cultura y Representaciones Sociales, 12(24), 51-95. 
Frigerio, A. (2020). Encontrando la religión por fuera de las "religiones": Una propuesta para visibilizar el amplio y rico mundo social que hay entre las “iglesias" y el "individuo". Religião e Sociedade, 40(3), 21-47.

Frigerio, A. (en prensa). Religión, by any means necessary: ejemplos de toda esa diversidad religiosa a nuestro alrededor. Etnografías Contemporáneas, (12).

Frigerio, A. y Wynarczyk, H. (2008), Diversidad no es lo mismo que pluralismo: cambios en el campo religioso argentino y lucha de los evangélicos por sus derechos religiosos (1985-2000). Sociedade $e$ Estado, 23(2), 227-260.

García Risso, C. R. (2010). La misión cristiana de la Madre María: sus enseñanzas y profecías. Buenos Aires: Aol.

Garelli, R. (1966). Brujos y curanderos: de Pancho Sierra a la Madre María. Mercedes, Buenos Aires: Spalla.

Geertz, C. (1973). Religion as a cultural system. En C. Geertz (comp.), The Interpretation of Cultures (pp. 87-125). Nueva York: Basic Books.

Horvath, R. (1977). Los manosantas. Buenos Aires: Todo es Historia.

Leone, M. C. (1992). Un caso de religiosidad popular urbana: el culto a la Madre María en Buenos Aires. En D. Santamaría (ed.), Ocultismo y espiritismo en la Argentina (pp. 79-88). Buenos Aires: Centro Editor de América Latina.

Ludueña, G. (2007). Imagen y re-construcción de identidad en el espiritismo argentino. En J. I. Follmann y J. R. Lopes (orgs.), Diversidade religiosa, imagens e identidades (pp. 87-112). Porto Alegre: Armazén Editorial.

Martínez, A. T. (2013). En torno a la noción de campo religioso: categorías para estudiar religión y política en America Latina. En V. Giménez Beliveau y E. Giumbelli (coords.), Religión, cultura y política en las sociedades del siglo XX (pp. 87-107). Buenos Aires: Biblos/ACSRM.

Maurizi, A. (1968). "Entre la duda y la fe: la Madre María". en Todo es Historia 9. pp. 9-18. 
McGuire, M. (2007), Sacred place and sacred power: Conceptual boundaries and the marginalization of religious practices. En P. Beyer y L. Beaman (eds), Religion, Globalization and Culture (pp. 57-77). Boston: Brill.

Miguel, G. (2013). Meios de comunicação e religiosidade. Mediações e perspectivas midiáticas na concepção das comunicações evangélicas. Rever, 13(1), 197-212.

Míguez, D. (2002). El protestantismo popular en la Argentina: las lógicas de expansión del pentecostalismo durante el siglo XX. Anuario IEHS, (17), 163-199.

Orsi, R. (2005). Between Heaven and Earth: The Religious Worlds People Make and the Scholars Who Study Them. Princeton: Princeton University Press.

Parker, C. (2010). El eclesiocentrismo en los clásicos de la sociología occidental. En D. Gutiérrez Martínez (ed.), Religiosidades y creencias contemporáneas (pp. 47-69). Zinacantepec: El Colegio Mexiquense.

Ratier, H (1972). La medicina popular. Buenos Aires: Centro Editor de América Latina.

Santamaría, D. (1992). Ocultismo y espiritismo en la Argentina. Buenos Aires: Centro Editor de América Latina.

Saracco, N. (1989). Argentine pentecostalism: its history and theology. (Tesis doctoral para optar al grado de Doctor of Philosophy). Birmingham University, Birmingham, Inglaterra.

Saracco, N. (1992). Peronismo y pentecostalismo: sustitución del liderazgo carismático durante la caída de Perón. Religión y Sociedad en Sudamérica, (1), 45-52.

Semán, P. (2001). Cosmológica, holista y relacional: Una corriente de la religiosidad popular contemporánea. Ciencias Sociales y Religión/Ciências Sociais e Religião, (3), 45-74.

Semán, P. (2002). Literatura e religião na sociedade contemporânea. Imaginario, (8), 263-271. 
Semán, P. (2013). Pentecostalismo, política, elecciones y poder social. Cultura \& Religión, 7(1), 60-81.

Semán, P. y Battaglia, A. (2012). De la industria cultural a la religión: nuevas formas y caminos para el sacerdocio. Civitas, 12(3), 439-452.

Semán, P. y Rizo, V. (2013). Tramando religión y best sellers: La literatura masiva y la transformación de las prácticas religiosas. Alteridades, 23(45), 79-92.

Suárez, H. (2006). Pierre Bourdieu y la religión: una introducción necesaria. Relaciones, 27(108), 19-27.

Stark, R. y Finke, R. (2000). Acts of Faith: Explaining the Human Side of Religion. Berkeley: University of California Press.

Viotti, N. (2015). El affaire Ravi Shankar: neo-hinduismo y medios de comunicación en Argentina. Sociedad y Religión, (43), 13-46.

Viotti, N. (2018). Psicología positiva y cultura de masas. Una mirada descentrada sobre los saberes del yo en la Revista Ohlalá. En M. B. Plotkin, C. Daniel y J. Caravaca (comps.), Saberes desbordados. Historias de diálogos entre conocimientos científicos y sentido común (Argentina, siglos XIX y XX) (pp. 244-264). Buenos Aires: IDES.

Wynarczyk, H. (2009). El río fluye en tierra seca: la primera gran movilización evangélica en Argentina, carisma peronista y agencia de Perón. Si Somos Americanos, 10(1), 1-22.

Zielicke, S. (2012). The role of american evangelist Tommy Hicks in the development of Argentine pentecostalism. En M. Wilkinson (ed.), Global Pentecostal Movements: Migration, Mission and Public Religion (pp. 135-152). Boston: Brill. 
* Doctor en Antropología, Universidad de California. Investigador principal del CONICET (Consejo Nacional de Investigaciones Científicas y Técnicas) con sede en el Instituto de Investigaciones de la Facultad de Ciencias Sociales de la Universidad Católica Argentina. Profesor en la Maestría en Antropología Social y Política de FLACSO. Coordinador de la red DIVERSA (Diversidad Religiosa en Argentina). Fue presidente de la Asociación de Cientistas Sociales de las Religiones en el Mercosur, organizador de las tres primeras Jornadas sobre Alternativas Religiosas en Latinoamérica y Paul Hanly Furfey Lecturer de la Association for the Sociology of Religion (EE.UU.). alejandrofrigerio@gmail.com 